\title{
Na Síndrome de Turner a Função Tireoidiana Não Deve Ser Esquecida
}

\begin{abstract}
$\Delta$
Ś́NDROME DE TURNER CARACTERIZA-SE pela perda parcial ou total de um cromossoma sexual, resultando em indivíduos femininos, com características fenotípicas variáveis. São comumente mais observados: a baixa estatura, hipogonadismo, malformações cardíacas e renais e outras anormalidades, entre elas o pescoço alado e o linfedema. A suspeita clínica ocorre no período perinatal pela presença de linfedema ou malformação cardíaca, na infância pela baixa estatura e, na época da puberdade pelo hipogonadismo. O diagnóstico deve ser sempre confirmado pelo cariótipo, já que o fenótipo pode ser confundido com a Síndrome de Noonan, ou nos casos óligo sintomáticos com outras condições clínicas. $\mathrm{O}$ endocrinologista é procurado geralmente pela baixa estatura na infância, ou pelo hipogonadismo na época puberal e deve estar atento a outras alterações geralmente de origem autoimune como o diabetes mellitus e a disfunção tireoidiana (1-3).

Os relatos sobre a Síndrome de Turner iniciam-se no século 16, com o anatomista Giovanni Morgagni em 1768, descrevendo a autópsia de uma mulher pequena com hipogonadismo e malformação renal. Só em 1902, encontram-se novos relatos, onde Funke descreve uma menina de 15 anos com baixa estatura, pescoço alado, linfedema congênito e hipogonadismo. Em 1925, Sheresewskii documenta uma mulher de 25 anos com o clássico fenótipo, e em 1929, em um Encontro da Sociedade Pediátrica de Munique, Ulrich apresenta uma menina de 8 anos com pescoço alado e outros estigmas. A síndrome é nomeada em 1938, quando o americano de Oklahoma Henry Turner, relata sete mulheres com baixa estatura e infantilismo sexual, que ele atribuiu ser conseqüente à insuficiência hipofisária. A origem do hipogonadismo foi redefinida em 1942 por Fuller Albright, que comprovou a insuficiência ovariana. $\mathrm{O}$ relacionamento entre o fenótipo da Síndrome de Turner e as alterações cromossomiais, são relatadas somente a partir de 1954 por Paolo Polani e Charles Ford e publicadas em 1959. A síndrome é conhecida como Turner na literatura médica americana e inglesa, como Ulrich-Turner no continente europeu e como Sheresewski's na Rússia $(3,4)$.

A alteração da glândula tireóide na Síndrome de Turner foi descrita pela primeira vez também em autópsia, por Atria e colaboradores (5), em 1948, que observaram em uma jovem com Síndrome de Turner a presença de glândula tireóide pequena e com infiltrado linfocitário. Atualmente é relatada alteração da função tireoidiana em cerca de $30 \%$ das pacientes (2), sendo descrita a presença de anticorpos antitireoidianos em freqüência variável de 22 até cerca de $60 \%$ das pacientes, e hipotireoidismo (clínico e subclínico) em cerca de $30 \%$ (2). Já o hipertireoidismo incide de maneira semelhante à população em geral (3). Nos estudos longitudinais, observase um aumento da incidência da doença tireoidiana com o correr dos anos (5), sendo referido que existe uma maior prevalência de anticorpos naquelas que apresentavam o cariótipo com isocromossoma de $\mathrm{X}(6)$ e que a perda do braço curto e a duplicação do braço longo, parecem ter importân-
\end{abstract}

editorial

\section{Marilia Martins Guimarães JoÃo Gabriel H. Cordeiro}

Professora Associada, Disciplina de Endocrinologia, Universidade Federal do Rio de Janeiro, RJ (MMG); Professor Titular em Endocrinologia, Universidade Federal do Rio de Janeiro e Diretor, Instituto de Endocrinologia da Santa Casa de Misericórdia do Rio de Janeiro, RJ (JGHC) 
cia nos processos de desenvolvimento de autoimunidade (5). Os estudos da morfologia da glândula tireóide utilizando exames de imagens são mais escassos e em sua maioria são realizados por pesquisadores do leste europeu, escritos em língua nativa.

Neste número dos ABE\&M, a Dra. Medeiros e seus colaboradores publicam um artigo bastante interessante sobre a função tireoidiana na Síndrome de Turner (7), onde eles analisam a partir de uma coorte de 70 pacientes, uma amostra de $24(34,2 \%)$ que apresentaram em alguma época alteração da função tireoidiana e as estuda de uma maneira mais detalhada utilizando métodos de imagem. A função tireoidiana apresentouse permanentemente alterada em 13 pacientes, sendo nove com TSH elevado e dentre estas três com hipotireoidismo franco necessitando reposição. Destas três, apenas a mais velha apresentava anticorpos positivos e as demais negativos. Uma das pacientes era bastante jovem com apenas 1 ano e 6 meses de idade. Estes mesmos autores em publicação anterior, estudando a função tireoidiana não haviam encontrado hipotireoidismo antes dos 4 anos de idade como é relatado na literatura em geral $(1,8)$. É interessante na reavaliação das pacientes, o achado do desaparecimento de anticorpos em pacientes que não desencadearam hipotiroidismo, $o$ que sugere que um comportamento variável no estado imunitário e que contraria a orientação de não haver necessidade de reavaliação uma vez que estes positivos (3) podem ser negativados. Observa-se que após os 20 anos de idade todas as pacientes apresentavam positividade de anticorpos o que provavelmente reflete a progressão do desencadeamento da autoimunidade com o avanço da faixa etária. A avaliação com o pertecnetato mostrou normalidade em sua maioria tanto na captação como na distribuição do traçador na glândula tireóide. A avaliação ultrassonográfica apresentou resultados interessantes. Apenas uma paciente apresentou resultados dentro da normalidade e foram encontrados aumento do volume da tireóide em 21 (91\%) e diminuição em duas. Este achado discordante da literatura, talvez se deva à diferença de métodos para a correção do volume considerando a estatura das pacientes, já que na literatura os resultados encontrados dos volumes tireoidianos em crianças são bastante discordantes entre as séries apresentadas (9). Quase todas as pacientes apresentavam alterações da textura, bordos e de ecogenicidade. Esta alta prevalência provavelmente se deve à amostra estudada, uma vez que todas as pacientes haviam apresentado em alguma época alteração da função tireoidiana.

Os estudos sobre a morfologia tireoidiana relativos à Síndrome de Turner, são realizados em pacientes com e sem alteração da função tireoidiana, resultando numa prevalência menor de alterações ultrasonográficas. As alterações de textura não se correlacionaram com os achados à cintilografia, embora a paciente que apresentou maior número de alterações ao USG, foi a única que apresentou distribuição irregular do traçador. O ultra-som mostrou ser um exame mais sensível na detecção de alterações morfológicas da glândula tireóide.

Finalizando, o trabalho aqui apresentado por Medeiros e colaboradores (7) traz um questionamento ao consenso publicado em janeiro deste ano que recomenda avaliação anual da função tireoidiana a partir dos 4 anos (1) e da dosagem de anticorpos antitireoidianos a partir dos 10 anos e que uma vez positivados não existe a necessidade de repeti-los (3). Além disso, Medeiros e colaboradores nos sinalizam duas posturas: a conduta expectante quanto à intervenção terapêutica, pois a função tireoidiana apresentou-se normal em grande parte dos pacientes quando reavaliada, e o bom senso anteriormente sugerido por Gravholt (2) de avaliarmos os anticorpos e a função tireoidiana ao diagnóstico e a função tireoidiana anualmente.

\section{REFERÊNCIAS}

1. Bondy CA, for The Turner Syndrome Consensus Study Group. Care of girls and women with Turner syndrome: A guideline of the Turner Syndrome Study Group. J Clin Endocrinol Metab 2007;92:10-25.

2. Gravholt $\mathrm{CH}$. Clinical practice in Turner Syndrome. Nat Clin Pract Endocrinol Metab 2005; 1:41-52.

3. Elsheikh M, Dunger DB, Conway GS, Wass JAH. Turner's syndrome in adulthood. Endocr Rev 2002;23:120-40.

4. http://www.whonamedit.com/synd.cfm/1064.html - acessado em abril de 2007

5. El-Mansoury M, Bryman I, Berntorp K, Hanson C, Wilhelmsen $L$, Landin-Wilhelmsen $K$. Hypothyroidism is common in Turner syndrome: results of a five-year follow-up. J Clin Endocrinol Metab 2005;90:2131-5.

6. Elsheikh M, Wass JAH, Conway GS. Autoimmune thyroid syndrome in women with Turner's syndrome - the association with karyotype. Clin Endocrinol (Oxf) 2001;55:223-6.

7. Medeiros CCM, Lemos-Marini SHV, Brícola-Filho M, Camargo EE, Santos AO, Magna LA, et al. Evidências de doença tireóidea auto-imune crônica subclínica em portadoras da síndrome de Turner. Arq Bras Endocrinol Metab 2007,51:401-409

8. Medeiros CC, Marini SH, Baptista MT, Guerra Jr G, MacielGuerra AT. Turner's syndrome and thyroid disease: a transverse study of pediatric patients in Brazil. J Pediatr Endocrinol Metab 2000;13:357-62.

9. Delange F. What do we call a goiter? Eur J Endocrinol 1999;140:486-88.

\section{Endereço para correspondência}

Marilia Martins Guimarães

Rua Humberto de Campos 974 - apto 1504

22430-190 Rio de Janeiro, RJ

Email: marguima@openlink.com.br 